\title{
O Moderno Arcaísmo Nacional: investimento estrangeiro direto e expropriação territorial no agronegócio canavieiro
}

\author{
Wendell Ficher Assis ${ }^{1}$
}

\begin{abstract}
Resumo: Este trabalho visa compreender as reconfigurações territoriais desencadeadas no meio rural brasileiro a partir do início dos anos $2000 \mathrm{em}$ decorrência da expansão dos monocultivos de cana destinados à produção de agrocombustíveis, bem como analisa a origem e montante dos investimentos estrangeiros diretos aplicados na produção brasileira de etanol. Para tanto, utiliza uma abordagem teórica que considera a existência de conflitos ambientais e territoriais associados à lógica operatória de exploração capitalista da natureza, e busca elucidar a presença de discursos hegemônicos direcionados a invisibilizar modos distintos e não dominantes de uso e apropriação dos recursos naturais. Ademais, inspirada nas contribuições deintelectuaislatino-americanos aglutinados no que se denominou chamar paradigma modernidade-colonialidade, irá propor que a apropriação assimétrica dos recursos naturais tem sido parte integrante de uma condição de colonialidade na apropriação da natureza. Para sustentar essas análises, o artigo se vale da realização de dois trabalhos de campo conduzidos em áreas de expansão da monocultura de cana nos estados de Minas Gerais, São Paulo e Mato Grosso do Sul e do uso de estatísticas oficiais cotejadas pelo IBGE e pelo Banco Central.
\end{abstract}

Palavras-chaves: monocultura de cana, investimento estrangeiro direto, reconfiguração territorial.

Abstract: This paper aims to understand territorial reconfigurations triggered in the Brazilian countryside from the early 2000s due to the expansion of monocultures of sugarcane for the agrofuels' production. For this, it uses a theoretical approach that considers the existence of environmental and territorial conflicts associated with the operative logic of capitalist exploitation, and seeks to elucidate the presence of hegemonic speeches aimed to become invisible distinct and non-dominant modes of use and ownership of natural resources. The construction of the argument will use concepts considered obsolete by the academic doxa, such as imperialism, dependency, and primitive accumulation. Moreover,

1. Instituto de Ciências Sociais da Universidade Federal de Alagoas. Professor Adjunto. Instituto de Pesquisa e Planejamento Urbano e Regional da Universidade Federal do Rio de Janeiro. Pesquisador associado. E-mail: wwficher@yahoo.com.br 
inspired by the contributions of Latin American intellectuals agglutinated in the so-called paradigm modernitycoloniality, the article will propose that the asymmetric ownership of natural resources has been part of a condition of coloniality in the appropriation of nature.

Key-words: monoculture of sugarcane, foreign direct investment, territorial reconfiguration.

Classificação JEL: Q17.

\section{Introdução}

O avanço contínuo da monocultura de cana, acentuado durante os anos 2000, sobretudo em razão da produção de etanol com vistas ao atendimento do mercado internacional, tem reconfigurado as formas de apropriação territorial em diversas regiões brasileiras. Como a apreensão do mundo concreto não é dada de imediato e para apreendê-lo se faz necessário passar pela abstração (LEFEBVRE, 1995), esse artigo se vale de construções conceituais tais como conflitos ambientais, modos subordinados de se pensar a apropriação da natureza, resistência de movimentos sociais, espoliação de populações camponesas e permanência de uma lógica de exploração territorial calcada na colonialidade. Tentar-se-á articular a problemática teórica assim construída com o conhecimento empírico das modificações territoriais concretas, num movimento que permitirá submeter à interrogação certos aspectos da realidade social, bem como fazer girar a espiral que conecta abstração conceitual e práxis (BOURDIEU et al., 2007).

No Brasil, a expansão da monocultura de cana destinada à produção de agrocombustíveis ${ }^{2}$

2. A perspectiva adotada neste trabalho não se vê representada na noção de biocombustíveis, uma vez que essa denominação traz consigo uma aceitabilidade social que vincula a produção de combustíveis agrícolas à uma matriz energética limpa e sustentável. Ao contrário disso, vem sendo legitimada por empresários e governantes, num cenário marcado pela ausência de pesquisas que realcem os conflitos territoriais e ambientais subjacentes à apropriação assimétrica dos recursos naturais, bem como iluminem suas inter-relações com as estruturas de poder vigentes no sistema-mundo colonial/moderno (QUIJANO e WALLERSTEIN, 1992). Este trabalho visa, portanto, ocupar uma lacuna, refletindo sobre o modo através do qual a produção de agrocombustíveis contribui para manter uma modernidade colonizadora dos espaços, que se sustenta na exploração de territórios habitados, tradicionalmente, por segmentos sociais vulnerabilizados, tais como povos indígenas, populações camponesas, ribeirinhos, quilombolas, dentre outros.

Para lograr esse objetivo a pesquisa estruturou-se em duas frentes interpenetráveis: uma se alicerça em dois trabalhos de campo desenvolvidos em áreas de expansão de monoculturas de cana, através dos quais se almejou captar os discursos que se forjam a partir da atuação de movimentos sociais, sindicatos e populações camponesas, que vivenciam os conflitos decorrentes da expansão canavieira. ${ }^{3}$ Em outra, o tra-

optou-se por utilizar a designação agrocombustíveis no intuito de enfocar a natureza agrícola e rural da produção desse insumo energético.

3. A realização das pesquisas de campo transcorreu em dois momentos; o primeiro entre 22 de novembro e 23 de dezembro de 2006 e o segundo no período de 08 a 27 
balho focaliza a análise dos dados de montante e origem dos investimentos estrangeiros diretos aplicados na produção de etanol, para indicar que a produção de agrocombustíveis tem sido uma maneira lucrativa de se evitar a desvalorização de capitais sobreacumulados nas economias cêntricas; de modo que a reordenação territorial operada pelo monocultivo de cana representa, ao mesmo tempo, a expansão geográfica dos domínios do capital e uma maneira lucrativa de se empregar capitais ociosos. Ademais, pode-se sugerir um entrecruzamento entre as crises financeira e climática através do qual se criam novos mercados que, alavancados pelo discurso da preservação ambiental, transformam a degradação do ar, água, solos e das populações em novos circuitos de acumulação. Embora a natureza tenha sido convertida em objeto de domínio da ciência e da produção, ao mesmo tempo em que foi externalizada do sistema econômico, a saber, de sua conexão operacional ao sistema de preços, observa-se hoje o surgimento de lutas sociais ambientalizadas, cujas origens remontam ao histórico de resistência aos modelos colonialistas e imperialistas. Ao promover uma análise que realça a junção entre as dinâmicas concretas de reconfiguração territorial e os fluxos de investimentos estrangeiro direto direcionado à produção de etanol, almeja-se sustentar que o avanço da monocultura de cana representa um alargamento da exploração capitalista da natureza que, alicerçada no discurso da preservação ambien-

de maio de 2010. No somatório das duas incursões foram percorridas regiões de três estados brasileiros: Triângulo Mineiro, em Minas Gerais; Oeste Paulista, em São Paulo e a mesorregião sudoeste de Mato Grosso do Sul. Durante os trabalhos de campo foram realizadas entrevistas estruturadas e semiestruturadas com e sem registro em áudio, bem como anotações em cadernos de campo. O objetivo foi contemplar uma gama variada de atores sociais que possibilitasse construir uma nova mirada acerca da expansão dos monocultivos de cana. As entrevistas incluem representantes de sindicatos de trabalhadores rurais, entidades governamentais de assistência técnica rural, integrantes de populações indígenas, pequenos agricultores, representantes da Comissão Pastoral da Terra, cortadores de cana, representantes do Centro Indigenista Missionário, comerciantes locais, garotas de programa, assentados da reforma agrária, arrendatários de terra, políticos e representantes de cooperativas rurais. tal, mantém uma modernidade colonizadora dos espaços e territórios locais.

Na perspectiva que orienta esse artigo, o processo de acumulação primitiva é estrutural e está sempre se reatualizando e ressurgindo; assim, o argumento se vale da ideia de uma acumulação primitiva incessante em que a questão referente aos elementos materiais da acumulação de capital, longe de estar resolvida pela forma material da mais-valia, transforma-se em outra questão: para utilizar produtivamente essa mais-valia realizada, torna-se imprescindível que o capital progressivamente disponha de maior quantidade de terras para poder fazer uma seleção quantitativa e qualitativamente ilimitada de seus meios de produção (LUXEMBURGO, 1970). Com base nesse raciocínio, os argumentos aqui mobilizados procurarão evidenciar que os monocultivos de cana para a produção de agrocombustíveis representam um alargamento das bases de acumulação de capitais e de controle sobre novos territórios, ao mesmo tempo em que engendram novas formas de dependência, tais como subordinação de pequenos agricultores, espoliação de populações camponesas, mercantilização da natureza e subserviência à mobilidade do capital. Essas novas formas de dependência mantêm a reprodução ampliada do capital em interconexão com o contínuo processo de acumulação primitiva.

\section{Acumulação primitiva e produção de agrocombustíveis: a inserção de novos territórios nos circuitos do capital}

A acumulação capitalista é analisada por Luxemburgo (1970) como sendo uma espécie de metabolismo que se verifica entre os modos de produção capitalista e as formações sociais de traços pré-capitalistas. Sem essas últimas, a acumulação não se pode verificar, mas, ao mesmo tempo, ela consiste na desintegração e assimilação das porções pré-capitalistas. A condição vital da acumulação capitalista se traduz, portanto, numa dissolução progressiva e contínua das for- 
Tabela 1. Área plantada com soja Brasil e regiões 2001-2008 (ha)

\begin{tabular}{|c|c|c|c|c|c|c|c|c|c|}
\hline \multirow{2}{*}{$\begin{array}{c}\text { Mesorregião } \\
\text { Geográfica }\end{array}$} & \multicolumn{8}{|c|}{ Ano } & \multirow{2}{*}{$\begin{array}{c}\text { Taxa de } \\
\text { crescimento }\end{array}$} \\
\hline & 2001 & 2002 & 2003 & 2004 & 2005 & 2006 & 2007 & 2008 & \\
\hline Brasil & 13988351 & 16376035 & 18527544 & 21601340 & 23426756 & 22082666 & 20571393 & 21063721 & $50,58 \%$ \\
\hline Norte & 106136 & 140656 & 212264 & 359434 & 514296 & 517943 & 455075 & 508024 & $378,65 \%$ \\
\hline Nordeste & 966165 & 1125225 & 1242515 & 1321505 & 1441161 & 1488313 & 1455734 & 1580796 & $63,62 \%$ \\
\hline Sudeste & 1162418 & 1294586 & 1527857 & 1876303 & 1900077 & 1665966 & 1361705 & 1396542 & $20,14 \%$ \\
\hline Sul & 5993431 & 6860846 & 7498175 & 8309827 & 8688656 & 8131849 & 8283922 & 8146896 & 35,93 \\
\hline Centro Oeste & 5760201 & 6954722 & 8046733 & 9734271 & 10882566 & 10278595 & 9014957 & 9431463 & $63,73 \%$ \\
\hline
\end{tabular}

Fonte: IBGE/PPM, 2009.

mações sociais compostas por traços pré-capitalistas. Como se espera poder clarificar com a análise das dinâmicas de reconfiguração territorial encetadas no meio rural brasileiro durante os anos 2000, o avanço da monocultura de cana em estados da região Centro-Sul tem sido um dos mecanismos que favorece o deslocamento em direção à região Amazônica de atividades intensivas no uso da terra como, por exemplo, pecuária e cultivo de soja, que, por sua vez, acabam por pressionar a integração de novos territórios e culturas na dinâmica de acumulação capitalista.

No Brasil, a ocupação de terras na região Centro-Sul, mais caras e com acesso às melhores condições logísticas, têm favorecido o agronegócio da cana em virtude de sua melhor rentabilidade econômica. Isso tem contribuído para impulsionar a migração da soja e da pecuária em direção às fronteiras agrícolas da região Amazônica, onde a fragilidade da fiscalização dos desmatamentos aliada às atividades ilegais de grilagem tem facilitado o aumento das áreas dedicadas à sojicultura e à pastagem. A esse respeito, a Tabela 1, apresentada a seguir, demonstra, na região Amazônica, a porção de terras ocupada com a produção de soja cresceu 378\% entre 2001-2008, período que coincide com a expansão da lavoura de cana na região Centro-Sul.

As frentes de expansão do agronegócio de cana e soja se entrelaçam e se deslocam mutuamente, pressionando o alargamento da fronteira agrícola e o desmatamento em zonas situadas nos estados da região Amazônica. Essas dinâmicas da economia geográfica possibilitam a inserção de novas terras nos circuitos de acumulação do capital, ao mesmo tempo em que promovem a expropriação de camponeses e populações tradicionais, tais como ribeirinhos, quilombolas e indígenas que secularmente habitam a Amazônia. Os monocultivos de cana e soja, aliados à produção pecuária, atividades que no Brasil são extensivas no uso da terra, reordenam a ocupação territorial, bem como impactam negativamente modos distintos e contra-hegemônicos de uso e apropriação dos recursos naturais. Assim, ao se analisar as estratégias de arrendamento ${ }^{4}$ de terras utilizadas pelo setor sucroalcooleiro para expandir sua ocupação no Centro-Sul vis-à-vis seus impactos nas dinâmicas de deslocamento da pecuária e da soja em direção à Floresta Amazônica ${ }^{5}$, pode se

4. O arrendamento de terras representa a base para a ampliação dos monocultivos de cana e desencadeia uma complexa alteração nos tipos de produção, na disponibilidade de terras e empregos, no fluxo migratório para cidades, na oferta de alimentos e na possibilidade de demarcação de territórios, tanto para a reforma agrária quanto para o estabelecimento de novas reservas indígenas. Isso pode ser notado no fragmento a seguir extraído de entrevista realizada durante os trabalhos de campo: "As usinas chegaram aqui e foram marcando território, selecionando as melhores terras e arrendando o que podiam. Agora fixam o preço e controlam tudo. É assim, o poder econômico é muito forte" (Entrevista com representante da Cooperativa de Empresários Rurais do Triângulo Mineiro - Uberaba/MG, 26 nov. 2006)

5. O avanço da cana sobre áreas ocupadas com soja e pecuária nos estados do Centro-Sul do País é apenas um dos fatores que vem contribuído para a migração dessas atividades em direção à fronteira agrícola, nesse universo de avanço do capitalismo no campo outras variáveis, tais como; aumento da demanda por soja e carne, políticas públicas de incentivo à colonização, melhoria da infraestrutura logística em estados da região Norte, estratégias de expansão dos negócios de pecuarista e sojicultores, também têm impulsionado o alargamento da ocupação territorial nos estados da região Amazônica. 
sugerir a existência de duas lógicas que afetam diferenciadamente pequenas, médias e grandes propriedades e, que, por sua vez, engendram distintos processos de reordenamento territorial e de migração de atividades para a fronteira agrícola.

O cálculo mercantil, não raro, perpassa a decisão pelo arrendamento tanto de pequenos e médios agricultores quanto de grandes proprietários de terra. No entanto, os pequenos e médios agricultores ativam os significados de pertencimento ao lugar, bem como da manutenção ou inviabilidade do pluricultivo ou da atividade leiteira, como mecanismos que influenciam na decisão de arrendar ou não as terras para o plantio de cana. ${ }^{6}$ Os que optam pelo arrendamento, invariavelmente, migram para as sedes urbanas dos municípios canavieiros, passando a ter como principal ingresso monetário a renda auferida do arrendamento. Esses agricultores que produziam os alimentos destinados à reprodução social de suas famílias, que dependendo das demandas da propriedade geravam empregos, assim como abasteciam os mercados locais com a venda de gêneros alimentícios, passam à condição de rentistas da terra, ao mesmo tempo em que deixam de ofertar alimentos e começam a demandá-los.

Por essa via, os arrendamentos alteram as dinâmicas de oportunidades de trabalho, de disponibilidade e demanda de alimentos, além de incidirem sobre os preços do mercado imobiliário rural e urbano; contudo, não desencadeiam processos de expropriação direta, uma vez que as transações obedecem aos imperativos do mercado de terras. Os traços que evidenciam essa dinâmica podem ser notados nas entrevistas transcritas a seguir, realizadas com o presidente do Sindicato dos Trabalhadores Rurais de Uberaba e com um pequeno agricultor de Água Comprida, municípios localizados no Triângulo

6. O trecho de entrevista transcrito a seguir ilustra esse tipo de ocorrência: "A gente aqui vai ficando exprimido. Tem gente que pensa diferente, tem sentimento pela terra, aí não arrenda pra cana, mas outros não aguentam e acabam cedendo. Eu estou ficando cercado pela cana, mas tenho desejo de ficar e vou resistir" (Entrevista com pequeno agricultor - Uberaba/MG, 26 nov. 2006).
Mineiro e afetados pela expansão da monocultura canavieira.

"A cana, como falei, foi boa para os comerciantes lá da cidade. Vem gente da zona rural, a pessoa precisa do alimento, aí vai lá comprar no supermercado. Para o pequeno produtor que sempre viveu da terra aqui, ele agora está vivendo de aluguel, do arrendamento das terrinhas dele, esses que já foram para cidade têm que comprar alimento lá. Te pergunto cadê a fartura de alimentos dentro da cidade? Não existe mais" (Entrevista com W. presidente do STR de Uberaba, 11 mai. 2010).

"No meu ponto de vista, antes da chegada da cana aqui na nossa região, a população rural estava mais ligada ao campo, aí a oferta de alimentação era maior e, com isso, os preços na cidade eram melhores. Agora que estão arrendando a zona rural para o plantio de cana, isso mudou. Aquele pequeno produtor que produzia seu sustento e vendia a sobra na cidade, agora com o arrendamento ele precisa é comprar porque parou de produzir sua alimentação. A fartura não é mais de alimento, mas de dinheiro no bolso" (Entrevista com pequeno agricultor G, Água Comprida, 12 mai. 2010).

Diferente dessa lógica de deslocamento que afeta pequenos e médios agricultores, o arrendamento ou a venda de grandes propriedades ocupadas com soja ou pecuária coloca em marcha um processo de alargamento da fronteira agrícola levado a cabo por mecanismos de acumulação primitiva em associação com dinâmicas do mercado de terras. ${ }^{7}$ No caso da exploração mercantil,

7. Em harmonia com os dados estatísticos que apontam um aumento do efetivo bovino nos estados da região Norte, as informações qualitativas coletadas nos trabalhos de campo de 2006 e 2010 indicaram os estados da Amazônia como novas fronteiras de acomodação do gado, que sucessivamente se deslocava e segue se deslocando em função do avanço do agronegócio canavieiro. Isso pode ser percebido no trecho disposto a seguir, que foi extraído de entrevista realizada com veterinário lotado em uma prefeitura do Triângulo Mineiro (MG): “Os tradicionais criadores de gado aqui da região do Triângulo estão arrendando ou vendendo as terras pra cana e indo criar gado em Tocantins, Rondônia e Mato Grosso" (Entrevista com veterinário da Prefeitura de Iturama/MG, 28 nov. 2006). 
o cálculo é estritamente econômico, os grandes proprietários arrendam ou vendem suas terras localizadas no Centro-Sul para a implantação da monocultura de cana, transferindo seus negócios de gado e soja para espaços localizados na região Amazônica, onde os preços por hectare são mais atrativos e as possibilidades de aquisição fraudulenta, maiores. Além de as terras adquiridas legalmente na fronteira possibilitarem aumento das propriedades em virtude do menor preço por hectare, esse deslocamento da pecuária e da soja catapulta a expropriação violenta de populações camponesas e tradicionais que, por não deterem a titulação dos territórios secularmente habitados, ficam sujeitas às pressões exercidas por sojicultores e pecuaristas. Por essa via, ocorre um contínuo processo de mercantilização das terras, alimentando um rearranjo jurídico na estrutura fundiária e propiciando a incorporação de novos espaços nos circuitos de acumulação do capital.

Embora não se possa afirmar categoricamente que o deslocamento da soja e da pecuária pela expansão da monocultura de cana tenha vinculação direta com formas violentas de ocupação de terras na fronteira agrícola, a intensificação dos conflitos nos últimos anos na região Amazônica, em consonância com as estatísticas oficiais de aumento do efetivo bovino ${ }^{8}$ e do plantio de soja, possibilitam sugerir que a produção de agrocombustíveis, ao contribuir com o deslocamento de atividades em direção à fronteira agrícola, tem colocado em curso processos de acumulação primitiva e de espoliação de populações camponesas. Como se pode notar no gráfico disposto a seguir, a expulsão de famílias camponesas e de populações tradicionais ${ }^{9}$ foi uma constante na região Amazônica durante o período 20032009, que coincide com a expansão canavieira no

8. O aumento do efetivo bovino nos estados da Amazônia foi recorrente entre 2003-2008, com índices que variaram em algumas mesorregiões entre $19 \%$ e $47 \%$, enquanto a média nacional se situou em 3,4\% (IBGE, 2010).

9. De acordo com o Fórum Permanente das Nações Unidas para Populações Autóctones, aproximadamente 60 milhões de pessoas no mundo correm o risco de serem expulsas de suas terras para cederem lugar aos cultivos necessários à produção de agrocombustíveis (HOUTART, 2010).
Centro-Sul do País, tendo sido expropriadas, em média, 1.380 famílias por ano, ademais foram verificados dois picos em 2005 e 2007, quando foram expulsas, respectivamente, 2.468 e 1.644 famílias. Ao se comparar esse período com os dados do início da década, nota-se que, em 2000, 2001 e 2002, as expulsões se situaram em um patamar extremamente inferior, quando foram expropriadas, respectivamente, 250, 330 e 361 famílias.

A expansão da fronteira agrícola tem sido mais forte no Pará, que representa uma das portas de entrada da soja e da pecuária na região Amazônica. Pode-se argumentar que o processo de acumulação primitiva e de expropriação camponesa tem sido mais intenso nos espaços para os quais primeiramente se expande a pecuária e a monocultura de soja, atividades que têm seu deslocamento parcialmente influenciado pelo avanço da produção canavieira. Ao se sobreporem os dados de famílias expulsas na Amazônia e no Pará, constata-se que $87,9 \%$ das famílias que foram expropriadas se localizavam no Pará. Por essa via, constata-se que a expansão das atividades econômicas no meio rural brasileiro tem sido acompanhada de mecanismos violentos de apropriação territorial e expulsão de famílias. Como se verá adiante, é factível associar o avanço da monocultura de cana para produção de agrocombustíveis, tanto à absorção de capitais sobreacumulados principalmente nas economias centrais, quanto com a ocorrência de processos associados à acumulação primitiva incessante.

Dito de outra maneira, a produção de agrocombustíveis associa a forma de reprodução ampliada do capital com a continuidade incessante da acumulação primitiva, uma vez que a reconfiguração territorial colocada em marcha pelo avanço da monocultura de cana influencia na espoliação de populações camponesas que são expulsas de suas terras pelo deslocamento das atividades agropecuárias para áreas localizadas na fronteira agrícola, sobretudo na região amazônica, expropriando comunidades e integrando novos territórios aos circuitos de acumulação. O ímpeto geral de toda lógica capitalista do poder não é o de fazer com que os territórios se 
Figura 1. Famílias expulsas da terra nos estados da Amazônia - 2000-2009

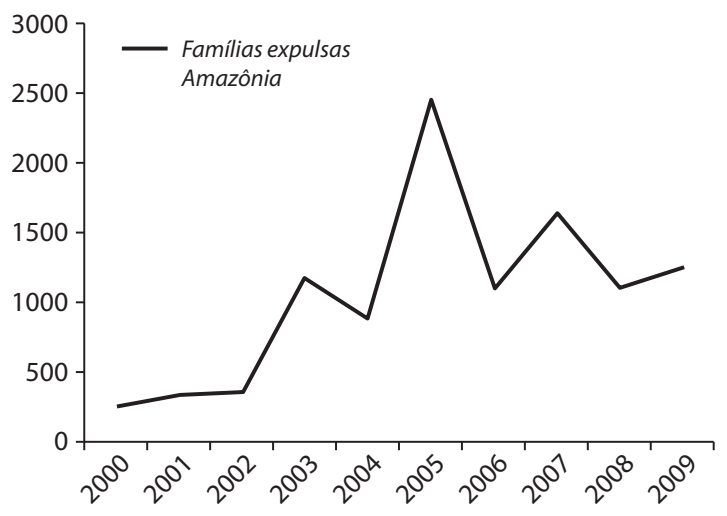

Fonte: CPT - Violência contra a ocupação e a posse. Elaboração do autor.

mantenham afastados do desenvolvimento capitalista, mas que estes sejam continuamente abertos e integrados (HARVEY, 2004). A produção de agrocombustíveis clarifica, portanto, o desenvolvimento de mecanismos de acumulação primitiva, que implicam no recurso a violência física e simbólica exercida sobre produtores rurais, onde grandes grupos financeiro-industriais organizam a combinação entre acumulação primitiva e acumulação "normal" (SERFATI, 2006).

\section{Investimento estrangeiro e expropriação territorial: a lógica imperialista na produção de etanol}

A produção brasileira de agrocombustíveis vem atraindo expressivos montantes de capital abruptamente territorializados em lugares dantes ocupados por populações tradicionais e pequenos agricultores, que têm seus espaços de reprodução econômica e cultural transformados pela homogeneidade do agronegócio monocultor. Para Harvey (2003), a criação de espaços, a organização de divisões territoriais de trabalho totalmente novas, a abertura de novas e mais baratas fontes de recursos, de novos espaços dinâmicos para acumulação de capitais e de penetração em estruturas sociais preexistentes às relações capitalistas são formas de absorver excedentes de capital e de mão de obra. Entretanto, esse avanço das formas de produção capitalistas não se processa num vácuo de resistências, contestações e de conflitos territoriais. Como se pode notar nos fragmentos transcritos a seguir, que foram extraídos de entrevistas realizadas durante os trabalhos de campo, as populações camponesas que habitam áreas consideradas prioritárias pelo agronegócio canavieiro têm se mobilizado e resistido ao avanço da monocultura;

"Eu estou meio espremido no meio da cana. Pelo que eu vejo, isso não gera desenvolvimento para região, eu vejo dizer que não está sendo bom para o município. Esse canavial que me rodeia é de uns seis alqueires [vinte e quatro hectares]. Eu estou ativo, quero trabalhar, quero continuar na minha terra. Já foram lá me propor arrendamento, mas eu disse que não. Se eu fizer isso vou ter que sair daqui e ir morar na cidade [...]. Essas terras são de herança; foram do meu bisavô, do meu avô e de meu pai. Existe uma história e eu faço parte dessa historia, tenho um sentimento para com essa terra e quero continuar aqui" (Entrevista com pequeno agricultor - Água Comprida/ MG, 12/05/2010).

"Concordo que o etanol é uma alternativa para o futuro, mas não destruindo tudo e massacrando nossos espaços. A gente bate aí, resiste, mas você sabe, a nossa voz é fraca. As usinas estão vindo pra cá e acabando com tudo. Eu 
não sei até quando vou aguentar, tenho medo de cair no desespero" (Assentado rural - Nova Alvorada do Sul/MS - região de expansão dos plantios de cana, 22/11/2006).

Não obstante a resistência contenha o ímpeto da ampliação canavieira, a expropriação violenta e o despojo de populações tradicionais foram e têm sido a tônica das dinâmicas de acumulação. É inegável que hoje em dia o capital opera desterritorializando importantes processos de produção e circulação, no entanto, ainda perdura sua lógica de controle e conquista de novos territórios, que são dedicados à produção de matérias-primas baratas (GROSFOGUEL, 2008). Harvey (2004), numa tentativa de qualificar esses novos movimentos do capitalismo, sugere o epíteto de novo imperialismo, descrevendo-o como sendo um projeto distintamente político da parte de atores cujo poder se baseia no domínio de um território e numa capacidade de mobilizar recursos naturais e humanos para fins econômicos, políticos e militares. Ademais, é integrado pelo fluxo de poder e por processos moleculares de acumulação do capital que estão dispersos no espaço e no tempo. Embora os mecanismos de controle e exploração dos territórios difiram no transcorrer das diferentes formas de imperialismo, seja por intermédio da anexação de colônias, pela invasão militar ou mesmo por intermédio de estratégias de dominação menos agressivas e visíveis, ${ }^{10}$ como a exportação de capitais financeiros e o protecionismo alfandegário, os objetivos da política imperialista têm historicamente se centrado na expansão da acumulação capitalista através da contínua expropriação e da integração de novos territórios aos circuitos do capital. ${ }^{11}$

10. No capitalismo moderno, a ação expropriatória se faz muito mais refinada, indireta e oculta. No interior dessa nova dinâmica os intelectuais, artistas, religiosos e moralistas podem até trabalhar para agentes da expropriação e acumulação, sem se sentirem ou se aperceberem partícipes de uma atividade degradante (SANTOS, 1978).

11. Heredia et al. (2010), em pesquisa sobre a sociedade e a economia do agronegócio, destacam o importante papel desempenhado pelo Estado na pavimentação da ocupação territorial. Na visão dos autores, embora a atuação estatal tenha sido minimizada pelos intérpretes neolibe-
A intensificação das exportações de capitais direcionadas ao Brasil para a exploração do complexo agromineral aprofunda o quadro de dependência econômica, além de representar uma saída para sobreacumulação de capitais que se tem verificado nas economias centrais. Nessa direção, Harvey (2004) esboça uma teoria da reordenação territorial como explicação e saída às contradições internas tendentes a gerar crises de acumulação. Desse modo, se é necessário evitar a desvalorização, é imperativo descobrir maneiras lucrativas de absorção dos excedentes de capital, de forma que a expansão geográfica e a reorganização espacial são imprescindíveis na elaboração de uma saída à crise. ${ }^{12}$ Aqui chama atenção, como veremos adiante, o fato de os investimentos efetuados na agroindústria canavieira terem origem no setor financeiro, historicamente oposto à imobilização de capital, especialmente por considerar a compra de terras como um mercado de baixa liquidez (LEITE e SAUER, 2011). A produção de agrocombustíveis pode, assim, ser apreciada como um novo ramo de negócio que, revestido por um discurso de preservação ambiental, absorve excedentes de capital acumulados nas economias centrais, alargando a reprodução ampliada, ao mesmo tempo em que organicamente desencadeia processos violentos de espoliação e expropriação de populações tradicionais e camponesas.

O argumento expresso por Harvey (2004) considera estranho qualificar de "primitivo" ou "original" um processo que segue em andamento no interior de nossas sociedades. Por esse motivo, utiliza em suas formulações teóricas o conceito de acumulação por espoliação para renomear a

rais, sua intervenção permanece forte, seja por intermédio de políticas setoriais relativas ao meio rural-agroindustrial, seja pela implantação de políticas mais amplas de infraestrutura, ou ainda através do estabelecimento de marcos regulatórios no campo das relações de trabalho e com o meio ambiente.

12. O capitalismo sobrevive não apenas por meio de uma série de reordenações espaços-temporais que absorvem excedentes de capital de maneiras produtivas, mas também por meio da desvalorização e destruição introduzidas como forma de enquadrar economias periféricas à lógica global (HARVEY, 2004). 
continuidade desse processo de acumulação primitiva. Entretanto, insiste que todas as características mencionadas por Marx (1975) para qualificar a acumulação primitiva permanecem fortemente presentes na geografia histórica do capitalismo. Na trilha desse processo contínuo, pode-se dizer que o avanço da monocultura de cana para produção de agrocombustíveis representa uma forma contemporânea dos métodos da acumulação primitiva, que compõe a escalada de destruição dos recursos ambientais globais (terra, ar, água), bem como impulsiona a degradação de ecossistemas e habitats, transformando-os em objetos da exploração agrícola através do emprego de práticas capital intensivas. Desse modo, é factível afirmar que resulta numa mercantilização da natureza e se enquadra como estratégia hodierna da incessante acumulação por espoliação (HARVEY, 2004).

Nesse cenário de expansão da monocultura de cana, o mercado de terras representa um importante componente que, por sua vez, tenciona a estabilidade das pequenas e médias propriedades rurais. Para Guedes et al. (2006), a dinâmica desse mercado é um indicador do vigor das atividades agropecuárias e das transformações na estrutura produtiva e auxilia no entendimento da relação mudança/permanência dos modos de produção de diferentes grupos sociais. No Brasil, a expansão da monocultura de cana tem sido facilitada por um mercado de terras pouco ordenado jurídica e socialmente, o que acarreta reflexos positivos nos custos de produção, ao mesmo tempo em que concentra a propriedade fundiária e inviabiliza os usos praticados pela agricultura camponesa. ${ }^{13}$ Em concomitância com a incorporação de

13. No Brasil, o plantio e processamento da cana-de-açúcar estão exclusivamente nas mãos do setor privado. O agronegócio canavieiro alcança os menores custos de produção do mundo, tanto para o açúcar como para o álcool, e desponta como altamente competitivo no mercado internacional (GONÇALVES, 2005). O plantio acontece nas propriedades das 432 usinas de açúcar e destilarias de álcool, bem como em áreas arrendadas que, somadas, alcançam uma extensão de 9 milhões e 616 mil hectares (MAPA, 2010; IBGE, 2012). Além disso, há aproximadamente 16.000 fornecedores independentes na região Centro-Sul do País, com propriedades de 150 hectares, em média, que vendem a cana para a indústria e contribuem com $22 \%$ da produção nacional (ORPLANA, 2010). novas terras nos circuitos de acumulação do capital, tem sido verificada uma internacionalização da propriedade fundiária levada a cabo sobretudo pelos investimentos estrangeiros empregados no agronegócio sucroalcooleiro. ${ }^{14}$ A esse respeito, Fernandes (2010) afirma que 69\% das terras brasileiras sob controle de estrangeiros se localizam nos estados de Mato Grosso, Goiás, São Paulo, Minas Gerais, Mato Grosso do Sul e Bahia, que têm se notabilizado como redutos do agronegócio sojicultor e canavieiro. Do mesmo modo, Sauer e Leite (2012) argumentam que a expansão de atividades do agronegócio, associadas ao incremento dos investimentos estrangeiros, tiveram como resultado um forte aumento nos preços das terras, comprometendo a situação de diversos segmentos sociais, que, frente a esse quadro, se viram forçados a se deslocarem para áreas mais distantes, tornando a questão de acesso à terra e ao território ainda mais complexa.

Os investimentos estrangeiros diretos aplicados na produção brasileira de etanol, que são uma forma de controle territorial ${ }^{15}$, cresceram rapidamente e de forma muito expressiva, passando de US\$ 5,4 milhões em 2004 para mais de US\$ 2,3 bilhões em 2007, ano no qual as transações atingem seu ponto culminante (BC/DESIG, 2010). Os dados sobre a origem dos investimentos estrangeiros diretos empregados no setor sucroalcooleiro no intervalo 2004-2009, período que coincide com a expansão da monocultura de cana desti-

14. Na ótica de Silva (2008), em conjunto com essa internacionalização da propriedade fundiária, tem ocorrido um avanço da expropriação e "descamponeização" já colocada em marcha há várias décadas, sobretudo, a partir do momento em que se consumaram a modernização da agricultura e a revolução verde. A expansão da monocultura de cana tem representado um alargamento desse processo, ademais, pode ser vista como expressão do fato de que as propriedades camponesas e capitalistas são territórios distintos, senão totalidades diferenciadas, onde se produzem relações sociais diferentes, que promovem modelos divergentes de desenvolvimento, havendo, portanto, uma disputa entre capital e campesinato (FERNANDES, 2007).

15. Em estudo que analisa a corrida mundial por compra de terras, Cotula (2012) sugere que, em países como Brasil e Argentina, a incorporação territorial por parte de estrangeiros tem se processado comumente através da compra de ações de empresas que possuem terras, ao invés de se dar por intermédio da aquisição direta das terras. 
Figura 2. Investimento estrangeiro direto aplicado na produção de etanol e com origem em paraísos fiscais (2004-2009)

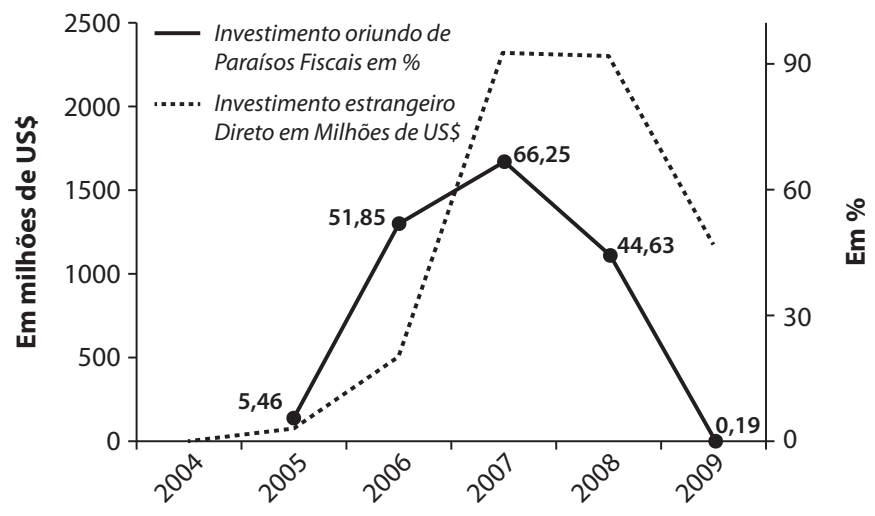

Fonte: BC/Departamento de Monitoramento do Sistema Financeiro e Gestão da Informação, 2010 - Sistematização e elaboração do autor.

nada à produção de agrocombustíveis, demonstram crescimento da atração de capitais da ordem de mais de $42.000 \%$. No intervalo de cinco anos, o agronegócio da cana atraiu mais de US\$ 6,3 bilhões de dólares em investimentos estrangeiros diretos; isso representou $5,4 \%$ de todos os investimentos estrangeiros diretos aplicados em todo o mercado brasileiro durante o mesmo período ${ }^{16}$. Quando se avaliam os países de procedência dos recursos, nota-se que, no período marcado pela crise financeira mundial, grande parte dos investimentos adveio de paraísos fiscais localizados no mar do Caribe. Ao se somarem os recursos originários das Bermudas, ${ }^{17}$ Ilhas Cayman, Ilhas Virgens e Ilhas do Canal Jersey, obtêm-se a cifra de US\$ 2,273 bilhões, valor que representa $66,2 \%$ dos investimentos estrangeiros no setor em 2007 e 44,6\% dos aplicados em 2008. A Figura 2 apresenta a proporção de investimentos estrangei-

16. Essa presença do capital internacional é também ressaltada por Leite e Sauer (2011) no que tange à trituração e processamento da soja. Nesse mercado, a participação estrangeira saltou de $16 \%$ em 1995 para $57 \%$ em 2005, caracterizando um forte processo de concentração econômica e de desnacionalização da produção.

17. Com apenas $53 \mathrm{~km}^{2}$ e 65.000 habitantes, o arquipélago das Bermudas é sede de 14.500 empresas estrangeiras, muitas delas gigantescas multinacionais. Nas ruas de Hamilton, a capital, podem ser encontrados representantes de $75 \%$ das 100 maiores companhias americanas e europeias (VEJA, 2002). ros diretos que saíram dos paraísos fiscais para serem aplicados no agronegócio sucroalcooleiro durante os anos da crise financeira mundial.

Esses dados do montante e origem dos investimentos estrangeiros diretos aplicados no setor sucroalcooleiro possibilitam indicar que a produção de agrocombustíveis tem sido uma maneira lucrativa de se evitar a desvalorização de capitais; assim, a reordenação territorial operada pelo monocultivo de cana representa, ao mesmo tempo, a expansão geográfica dos domínios do capital e uma maneira lucrativa de se empregar capitais sobreacumulados nos países cêntricos. A esse respeito, a rede médio-ambiental Indígena do Equador tem interpretado as estratégias comerciais de contenção das mudanças climáticas como novas formas de colonialismo; por conseguinte, cunharam o termo $\mathrm{CO}_{2}$ lonialismo para designar essas novas formas de imperialismo expressas pela produção de agrocombustíveis (HAZLEWOOD, 2010). Por intermédio da exportação de capitais, os monopólios comerciais e industriais procedem a uma exploração imprudente das riquezas naturais e dos recursos humanos dos países periféricos, realizando lucros substanciais e submetendo-os à influência e controle das economias centrais. A exportação de capital surge, portanto, como uma das principais estratégias de neocolonialismo em cujo interior se 
consolidam distintas formas de dominação imperialista (VAKHRUCHEV, 1975).

O aumento dos investimentos estrangeiros diretos no agronegócio sucroalcooleiro vem repercutindo na participação do capital internacional no processamento de cana. Entre as safras 2005/2006 e 2008/2009, o domínio estrangeiro passou de $5,7 \%$ para $12 \%$, crescimento de $110 \%$. Ao se considerar não somente o controle integral das ações, mas a participação estrangeira em empresas de capital aberto, essa cifra atinge $23 \%$ (SIAMIG, 2009) ${ }^{18}$. Na visão de Von der Weid (2009), o que está em jogo na produção de agrocombustíveis não é nem a mitigação do aquecimento global, nem a substituição de combustíveis fósseis em processo de esgotamento, mas um gigantesco movimento de algumas corporações internacionais e outras tantas nacionais pela obtenção de lucros estratosféricos. A participação de grupos estrangeiros na produção de etanol pode ser indicativa de novas relações de dependência levadas a cabo pelos frequentes deslocamentos de capital e pela expansão do poder das grandes corporações transnacionais. A ação econômica dessas corporações transnacionais e dos conglomerados financeiros no agronegócio sucroalcooleiro sugere, portanto, a existência de uma nova configuração centro-periferia, na qual o poder econômico incorporado em megacorporações age de forma policêntrica, engendrando multiperiferias.

Para muitas nações, a integração de suas economias ao livre mercado global levou à dependên-

18. As principais corporações transnacionais que já integram a produção nacional de etanol são: Abengoa Bioenergy (Espanha), Bunge e Cargil (EUA), Louis Dreyfus e Tereos (França), Shell e British Petroleum (Inglaterra), Noble (China) e Sojitz Corporation (Japão). A essas corporações, se somam os fundos de investimentos com origem nos conglomerados financeiros internacionais, dentre os quais se destacam: Infinity Bio, Clean Energy, Goldman Sachs, Brazil Renewable Energy Company, Global Foods, Carlyle e Discovery Capital (SIAMIG, 2009; JORNAL CANA, 2007). Essa presença crescente de firmas multinacionais na cadeia sucroalcooleira acarreta não somente uma redefinição da relação Estado-Economia no que se refere à soberania e à segurança energética do Brasil, mas também modifica os arranjos institucionais e organizacionais que sustentam toda a cadeia produtiva (FLEXOR, 2007). cia da natureza e à erosão dos projetos nacionais de desenvolvimento (CORONIL, 2000). Sob esse aspecto, a produção brasileira de agrocombustíveis pode ser vista tanto como reafirmação dessa dependência quanto como uma perpetuação de um projeto colonialista erigido a partir da exploração capitalista da natureza. Ao modo do que sugere Coronil (2003), pode-se enquadrar a produção de agrocombustíveis como tributária de um imperialismo global, no qual a natureza se transforma numa modalidade mais abstrata de riqueza, que passa a ser medida nos termos de valorização do capital. Ao ser tratada como capital no interior de uma economia mundial cada vez mais desregulada, a natureza, em suas múltiplas formas (exploração de produtos minerais e agrícolas ou turismo ecológico), converte-se na vantagem comparativa mais importante dos países localizados na periferia do capitalismo. Como exemplo disso, pode-se indicar que, mesmo sem a transformação do etanol em commodity com parâmetros internacionais, no período entre 2001 e 2008, as exportações de álcool, principalmente para EUA e União Europeia, cresceram 1.388\%, saltando de 341 milhões de litros para mais de 5 bilhões de litros (ALICEWEB, 2010), expressando a dupla função da expansão territorial da monocultura de cana: de um lado, ser espaço de alocação dos capitais cêntricos com consequente inserção de novos territórios nos circuitos de acumulação e, de outro, garantia de abastecimento do mercado externo com as ditas "energias limpas".

As estratégias do governo brasileiro no tocante à expansão da produção de etanol extrapolam o mero acesso aos mercados consumidores globais que será facilitado com os investimentos em infraestrutura logística que tem potencial para reduzir os custos de escoamento para exportação. Em trabalho conjunto do MRE (Ministério das Relações Exteriores) e do Mapa (Ministério da Agricultura, Pecuária e Abastecimento), tem-se incentivado o plantio de cana e a instalação de destilarias em países africanos como Botsuana, Congo, Gabão, Tanzânia, Senegal, Nigéria, Zimbábue, Moçambique e Angola, bem como em nações centro-americanas, principalmente El 
Salvador, Nicarágua e Guatemala. O projeto de inserção de países africanos e centro-americanos no circuito de produção do etanol, iniciado durante o governo do presidente Lula, ancora-se no discurso humanitário da redução da pobreza e da miséria, mas pode ser visto como uma tentativa de incluir novos países como produtores de etanol e alavancar a transformação do produto em uma commodity internacional. Essa estratégia foi delineada no documento Memorando de Entendimento entre o Governo da República Federativa do Brasil e o Governo dos Estados Unidos da América para Avançar a Cooperação em Biocombustíveis, firmado em março de 2007, que estabelece entre suas diretrizes que:

“Os participantes tencionam trabalhar conjuntamente para levar os benefícios dos biocombustíveis a terceiros países selecionados por meio de estudos de viabilidade e assistência técnica que visem a estimular o setor privado a investir em biocombustíveis. Os países tencionam começar a trabalhar na América Central e no Caribe encorajando a produção local e o consumo de biocombustíveis, com vistas a trabalhar conjuntamente em regiões-chave do globo" (MRE - Ministério das Relações Exteriores, 2007, p. 02).

O discurso da disponibilidade de terras e das vantagens comparativas, sempre acionado para justificar a expansão do agronegócio no Brasil, é igualmente empregado para legitimar o avanço da monocultura de cana nos países africanos. No entanto, a expansão no exterior estaria a cargo e sob a liderança de empresas brasileiras detentoras de uma expertise já consolidada. Isso pode ser constatado no pronunciamento do presidente Lula realizado durante a cerimônia de encerramento do Seminário Empresarial Brasil - Zâmbia, ocorrido em julho de 2010, em Lusaka:

"Olhando o mapa do mundo, onde a gente percebe que tem terra? É no continente africano e no continente latino-americano onde tem terra, onde tem sol e onde tem água e, portanto, nós temos que fazer disso uma vantagem comparativa na nova forma de investi- mento e de produção no século XXI. Queria dizer aos companheiros da Zâmbia que eu estou convencido, e vou repetir aqui uma coisa que eu tenho dito no Brasil: que a savana africana tem as mesmas características do cerrado brasileiro [...] E a tecnologia e o manejo do solo transformaram o cerrado brasileiro no maior produtor de grãos do mundo por hectare, em um grande produtor de cana-de-açúcar, em um grande produtor de milho, em um grande produtor de soja, em um grande produtor de qualquer coisa que a gente queira produzir no cerrado brasileiro. $\mathrm{E}$ isso, inexoravelmente, acontecerá com a savana africana, inexoravelmente. [...] Eu acho que, por isso, nós depositamos tanta fé e tanta esperança no continente africano e, sobretudo, levando em conta o potencial energético deste continente, não apenas pela quantidade de hidrelétricas que podem ser construídas aqui, financiadas por bancos brasileiros, construídas por empresas brasileiras. Não apenas por isso, mas pelo potencial da produção de etanol" (Discurso do presidente Lula durante encerramento do Seminário Empresarial Brasil-Zâmbia, Lusaka, Zâmbia, 8 jul. 2010).

No cenário exposto pelo presidente Lula, a entrada de territórios africanos nos circuitos de acumulação do capital estaria a cargo de empresas brasileiras, que com apoio do Estado, poderiam alavancar a integração africana no mercado mundial de insumos agrominerais, sobretudo de agrocombustíveis. A produção de etanol exemplifica, portanto, a dupla inserção brasileira no mercado internacional de commodities primárias: de um lado, atende as demandas cêntricas por energia e por novos territórios para investimento dos capitais sobreacumulados, e de outro, expande o modelo primário exportador às nações africanas e centro-americanas, que se integram ao sistema e são periferizadas por intermédio da atuação experta das megacorporações brasileiras. Nesse contexto de crescente presença do capital externo no Brasil, de aumento de exportações de etanol e de avanço de corporações brasileiras em territórios centro-americanos e africanos, o discurso do governo brasileiro que propala o etanol como 
uma saída para o problema das mudanças climáticas e de inserção das economias emergentes precisa ser contraposto ao cenário de ameaças às soberanias alimentar e energética que se concretizam na recorrente disputa por territórios. Para Borras Jr e Franco (2010), a confluência de varias crises globais (financeira, ambiental, energética, alimentar) tem contribuído para disparar uma corrida pelo controle de terras, especialmente daquelas situadas no sul global, onde atores econômicos nacionais e internacionais têm adquirido ou declarado a intenção de adquirir vastas extensões de terras pra construir ou ampliar suas explorações extrativas ou agroindustriais. Nessa luta desigual, as populações camponesas e comunidades tradicionais, como se pôde verificar por meio dos dados de expulsão de famílias na região amazônica, têm perdido o controle sobre suas terras e amargado a expropriação desencadeada pelo avanço do agronegócio monocultor.

Esse processo realça a continuidade da dominação e do submetimento dos povos mundo afora, que tem sido legitimado como uma necessária dimensão da modernidade, do desenvolvimento e do progresso econômico. Contudo, a análise aqui proposta calcada na ideia de uma colonialidade na apropriação da natureza, entendida tanto como resultado de formas econômico-instrumentais de se pensar e explorar o meio ambiente quanto como expressão de processos de expropriação territorial direcionados a sustentar a lógica prevalecente da acumulação capitalista, tem o mérito de clarificar o fato de nunca ter sido possível, nem poder vir a ser admissível modernidade sem colonialidade. $\mathrm{O}$ exemplo da dupla inserção brasileira na produção de agrocombustíveis elucida, portanto, os movimentos de uma acumulação primitiva incessante que continuamente busca incorporar novos espaços nos circuitos de valorização do capital, de modo a dispor de maior quantidade de terras para poder, assim, fazer uma seleção quantitativa e qualitativamente ilimitada de seus meios de produção (LUXEMBURGO, 1970).

\section{Do colonialismo de rapina à colonialidade na apropriação da natureza: a era dos agrocombustíveis}

Os estudos denominados pós-coloniais, subalternos ou pós-ocidentais, realizados desde África, Ásia e America Latina, entendidos não somente como espaço geográfico, mas como lugares que ativam o pensamento crítico emancipador, vêm articulando uma perspectiva que evidencia a faceta colonial da expansão capitalista e de seu projeto cultural (CAJIGAS-ROTUNDO, 2007). Nessa mirada, as Américas não foram incorporadas dentro de uma já existente economia mundial capitalista; pelo contrário, não haveria uma economia capitalista mundial sem a existência das Américas (QUIJANO e WALLERSTEIN, 1992). Quijano (2005) argumenta que esse processo começou com uma colonização interna de povos com identidades diferentes, mas que habitavam os mesmo territórios e foram convertidos em espaços de dominação interna. Esse fenômeno se desdobrou com a colonização imperial ou externa de povos que não só tinham identidades diferentes da dos colonizadores, como habitavam em territórios que não eram espaço de dominação interna dos colonizadores.

A expansão colonial iniciada no século XVI com as grandes navegações e o "descobrimento" das Américas, posteriormente incrementada com o neocolonialismo do final do século XIX, que promoveu a repartição da África e Ásia, é vista nessa abordagem como condição sine qua non para a existência e manutenção do capitalismo industrial. Por outro lado, a extinção do colonialismo histórico-político nas Américas, com a construção de nações independentes no século XIX, bem como na África e Ásia por intermédio da descolonização em meados do século $X X$, não foi condição necessária e suficiente para emancipação político-econômica e cultural dos países periféricos. Assim, a acumulação primitiva colonial, longe de ser uma pré-condição do desenvolvimento capitalista, foi um elemento indispensável 
da sua dinâmica interna e posterior continuidade (CORONIL, 2000). A esse respeito, Lander (2006) destaca que:

"Ao fazer abstração da natureza dos recursos, espaço e territórios, o desenvolvimento histórico da sociedade moderna e do capitalismo aparece como um processo interno, autogerado, da sociedade europeia, que posteriormente se expande para as regiões atrasadas. Nessa construção eurocêntrica, desaparece do campo de visão o colonialismo como dimensão constitutiva destas experiências históricas" (LANDER, 2006, p. 250).

Para compreender esse processo, Quijano (1997) cunhou o conceito de colonialidade como sendo algo que transcende as particularidades do colonialismo histórico e que não desaparece com a independência ou descolonização. Essa formulação é uma tentativa de explicar a modernidade como um processo intrinsecamente vinculado à experiência colonial. Essa distinção entre colonialidade e colonialismo permite explicar a continuidade das formas coloniais de dominação mesmo após o fim das administrações coloniais, além de demonstrar que essas estruturas de poder e subordinação passam a ser produzidas pelos mecanismos do sistema-mundo capitalista colonial-moderno (GROSFOGUEL, 2006). Assim sendo, a noção de colonialidade atrela o processo de colonização das Américas à constituição da economia-mundo capitalista, concebendo ambos como partes integrantes de um mesmo processo histórico iniciado no século XVI (CASTROGOMEZ e GROSFOGUEL, 2007).

A partir das trilhas já abertas pelo paradigma modernidade-colonialidade, esse artigo procura compreender o avanço da monocultura de cana para produção de agrocombustíveis como expressão de uma das lógicas da colonialidade. Para isso, lança mão da ideia de que há uma colonialidade na apropriação da natureza, entendida tanto como resultado da construção no interior da modernidade de formas econômico-instrumentais de se pensar e explorar o meio ambiente, quanto como expressão de processos de expro- priação territorial que sustentam a lógica prevalecente da acumulação capitalista e mantêm em funcionamento o sistema mundo colonial-moderno. A colonialidade na apropriação da natureza se refere, portanto, à existência de formas hegemônicas de se conceber e extrair recursos naturais, considerando-os como mercadorias, ao mesmo tempo em que representa o aniquilamento de modos subalternos de convívio com o meio ambiente, bem como a perpetuação e justificação de formas assimétricas de poder no tocante à apropriação dos territórios.

Se no colonialismo histórico a rapina dos recursos naturais se legitimava pela força e supremacia político-militar do Estado colonizador, no contexto de colonialidade na apropriação da natureza há outros mecanismos de poder que promovem a aceitabilidade da exploração territorial, dentre os quais se destacam: considerar a extração de riquezas naturais como vantagem comparativa no mercado de produtos primários, discurso da disponibilidade de terras vazias, degradadas e inexploradas, necessidade de tornar o território economicamente produtivo, criação da ideia-força de que o progresso e o crescimento econômico se atrelam à extração de riquezas naturais, conciliação e harmonia entre exploração capitalista da natureza e preservação ambiental, integração dos produtos primários à economia global como forma de pavimentar o caminho para era moderna. Dito em outros termos, durante o período do colonialismo histórico, a exploração de bens primários que foi levada a cabo através da mão visível da dominação política, agora está organizada por mecanismos de poder operados pela aparente mão invisível do mercado em associação com a destacada e necessária presença do Estado (CORONIL, 2000).

Como visto anteriormente, a expansão territorial e a dominação político-econômica das colônias foram condições indispensáveis para o desenvolvimento do capitalismo. No cenário atual, prescindindo de uma dominação política de corte colonial que desconhece a soberania dos povos, as grandes corporações empresariais e conglomerados financeiros têm se valido 
do poder econômico para expandir e incorporar novos espaços nos circuitos de acumulação do capital. Nesse sentido, o direcionamento de capitais para a produção de agrocombustíveis representa a continuidade da incorporação de novos territórios na lógica de acumulação capitalista, além de evidenciar a vigência de uma colonialidade na apropriação da natureza, tendo em vista que os recursos territorializados são visto como vantagem comparativa capaz de garantir a integração à economia global. É possível indicar que a exploração capitalista da natureza permanece sustentando a lógica que ampara a modernidade e mantém a colonialidade do poder em zonas consideradas periféricas (QUIJANO, 1997).

\section{Reflexões à guisa de conclusão}

Como se procurou clarificar, as frentes de expansão do agronegócio monocultor se entrelaçam e se deslocam mutuamente, pressionando o alargamento da exploração territorial e o desmatamento de zonas situadas na fronteira agrícola. Essas dinâmicas da economia geográfica possibilitam a inserção de novas terras nos circuitos de acumulação do capital, ao mesmo tempo em que promovem a expropriação de camponeses e populações tradicionais, tais como ribeirinhos, quilombolas e indígenas. Com base nas reflexões teóricas, trabalhos de campo e dados estatísticos cotejados neste trabalho, se pode afirmar que, no Brasil, as terras de fronteira foram e continuam sendo incorporadas sob os auspícios de uma estratégia que privilegia a produção capitalista no campo, sendo essa alicerçada em incentivos e políticas de Estado que estimulam a continuidade da grande exploração territorial direcionada à inserção brasileira na economia global, que nos anos recentes tem se tornado, ao mesmo tempo, periférica e periferizante.

A concentração fundiária vigente no País constitui, portanto, a espinha dorsal dos processos de acumulação capitalista no campo. Por essa via, pode-se concluir que o estudo de uma frente atual de expansão, a do agronegócio monocultor de cana, permite a análise concreta de um processo mais amplo que reproduz, em algumas de suas linhas gerais, uma etapa da própria formação histórica do Brasil, na medida em que as atuais frentes podem ser consideradas, de certa maneira, como as continuadoras da expansão e colonização territorial (VELHO, 1972, 1979). Na trilha desse processo contínuo e incessante, é plausível considerar que o avanço da monocultura de cana para produção de agrocombustíveis representa uma forma contemporânea dos métodos da acumulação primitiva, que compõe a escalada de mercantilização dos recursos ambientais globais (terra, ar, água), bem como impulsiona a degradação de ecossistemas e habitats, transformando-os em objetos da exploração agrícola através do emprego de práticas intensivas em capital. O capital, como relação complexa que é, segue desenvolvendo novas modalidades de emprego do trabalho social e da natureza, como parte indissociável de seu processo de valorização, que no interior do agronegócio articula tecnologias agronômicas de alta precisão, com níveis extremos de degradação socioambiental e trabalhista (SILVA e MARTINS, 2010). Nesse contexto, a persistência de uma estrutura agrária "arcaica" e altamente concentrada tem facilitado o avanço da monocultura de cana e se apresenta como funcional a esse novo ciclo de acumulação capitalista no campo.

\section{Referências bibliográficas}

ALICE Web: Banco de dados do Ministério do Desenvolvimento Indústria e Comércio. Disponível em: $<$ http://aliceweb.desenvolvimento.gov.br>. Acesso em: 12 nov. 2010.

BC - Banco Central/DIFIS - Diretoria de Fiscalização. Investimentos Estrangeiros Diretos. Disponível em: <http://www.bcb.gov.br/rex/ied/port/ingressos/htms/ index2.asp?idpai=INVEDIR > . Acesso em: 12 out. 2010.

Departamento de Monitoramento do Sistema Financeiro e Gestão da Informação. Disponível em: <http://www.bcb.gov.br/rex/ied/port/ingressos/htms/ index2.asp?idpai=INVEDIR $>$. Acesso em: 14 out. 2010. 
BOURDIEU, P.; CHAMBOREDON, J. C.; PASSERON, J. C. O oficio de sociólogo. Petrópolis: Vozes, 2007.

CAJIGAS-ROTUNDO, J. C. La biocolonialidad del poder. Amazonía, biodiversidad y ecocapitalismo. In: CASTRO-GOMEZ, S. e GOSFROGUEL, R. (Comp.). El Giro Decolonial. Reflexiones para una diversidad epistémica más allá del capitalismo global. Bogotá: Universidad Javeriana-Instituto Pensar, Universidad CentralIESCO, Siglo del Hombre, 2007.

CASTRO-GÓMEZ,S.eGROSFOGUEL,R. Prólogo.Giro decolonial, teoría crítica y pensamiento heterárquico. In: CASTRO-GOMEZ, S. e GOSFROGUEL, R. (Comp.). El Giro Decolonial. Reflexiones para una diversidad epistémica más allá del capitalismo global. Bogotá: Universidad Javeriana-Instituto Pensar, Universidad Central-IESCO, Siglo del Hombre, 2007.

CORONIL, F. Naturaleza del Poscolonialismo: Del eurocentrismo ao globocentrismo. In: LANDER, E. (Org.). La Colonialidad del Saber: Eurocentrismo y Ciencias Sociales, Buenos Aires, CLACSO, 2000.

¿Globalización Liberal o Imperialismo Global?

Cinco Piezas para Armar el Rompecabezas del Presente. Revista Temas, 33-34. Lisboa, abril-septiembre, p. 14-27, 2003.

COTULA, L. The international political economy of the global land rush: A critical appraisal of trends, scale, geography and drivers, The Journal of Peasant Studies, v. 39, n. 3-4, p. 649-680, 2012.

CPT - COMISSÃO PASTORAL DA TERRA. Conflitos no Campo Brasil. Goiânia: CPT, 2010. Disponível em: <www.cptnac.com.br>. Acesso em: 17 abr. 2010.

FERNANDES, B. M. Estrangeirização de terras na nova conjuntura da questão agrária. Conflitos no campo Brasil 2010. Goiânia, Comissão Pastoral da Terra, p. 76-81, 2011.

. Territórios da questão agrária: Campesinato, reforma agrária e agronegócio. Reforma Agrária, v. 34, p. 77-94, 2007.

FLEXOR, G. G. Investimentos Estrangeiros e Matrizes Energéticas. Carta Maior, 31 ago. 2007.

GONÇALVES, D. B. Mar de Canal, Deserto Verde? Dilemas do Desenvolvimento Sustentável na Produção Canavieira Paulista. Tese (Doutorado Engenharia de Produção). São Carlos: UFSCAR/CCET, 2005.

GROSFOGUEL, R. Del imperialismo de Lenin al imperio de Hardt y Negri: faces superiores del eurocentrismo. Universitas humanística, n. 65, p. 15-26, 2008.
- La descolonización de la economía política y los estudios postcoloniales: Transmodernidad, pensamiento fronterizo y colonialidad global. In Revista Tabula Rasa. Bogotá - Colombia, n. 4, p. 17-48, jan./jun. 2006

GUEDES, S. N. R. et al. Mercado de Terra e de Trabalho na (Re)Estruturação da Categoria Social dos Fornecedores de Cana de Ribeirão Preto. AGRIC/SP. São Paulo, v. 53, n. 1, p. 107-122, 2006.

HARVEY, D. O novo imperialismo. São Paulo: Edições Loyola, 2004.

. El nuevo imperialismo: sobre reajustes espaciotemporales y acumulación mediante desposesión.In Revista viento sur, España, 2003.

HAZLEWOOD, J. A. Más allá de la crisis económica: CO2lonialismo y geografías de esperanza. Iconos Revista de Ciencias Sociales, n. 36, enero-sin mes, 2010, pp. 81-95 Facultad Latinoamericana de Ciencias Sociales Ecuador.

HEREDIA, B., PALMEIRA, M. e LEITE, S. P. Sociedade e economia do "agronegócio" no Brasil. Revista Brasileira de Ciências Sociais, v. 25, n. 74, out. 2010.

HOUTART, F. A Agroenergia: solução para o clima ou saída da crise para o capital. Petrópolis: Ed. Vozes, 2010.

IBGE/PPM - Instituto Brasileiro de Geografia e Estatística. Pesquisa Pecuária Municipal 1974-2008. Disponível em: <www.sidra.ibge.gov.br/bda/pesquisas/ ppm/default.asp >. Acesso em: 24 abr. 2010.

LANDER, E. Marxismo, eurocentrismo y colonialismo. In: BORON, A., AMADEO, J. e GONZÁLEZ, S. (Comp.) La teoría marxista hoy: problemas y perspectivas, CLACSO, Buenos Aires, 2006.

LEFEBVRE, H. Lógica Formal, Lógica Dialética. Tradução de Carlos Nelson Coutinho. São Paulo, Civilização Brasileira, 1995.

LEITE, S. P. e SAUER, S. Expansión de agronegocios, mercado de tierras y extranjeirización de la propriedade em Brasil. Mundo Siglo XXI, v. VII, n. 26, p. 43-63, Ciecas, México, 2011.

LUXEMBURGO, R. A acumulação do capital: estudo sobre a interpretação econômica do Imperialismo. Rio de Janeiro: Zahar, 1970

MARX, K. O capital: critica da economia política. 2. ed. Rio de Janeiro: Civilização Brasileira, 1975.

MRE - Ministério das Relações Exteriores. Memorando de Entendimento entre o Governo da República Federativa do Brasil e o Governo dos Estados 
Unidos da América para Avançar a Cooperação em Biocombustíveis. Disponível em: <www.itamaraty. gov.br/>. Acesso em: 14 set. 2010.

QUIJANO, A. Don Quijote y los Molinos de Viento en América Latina. Revista Electrónica de Estudios Latinoamericanos, Área Sociología Histórica. Instituto de Investigaciones Gino Germani, Facultad de Ciencias Sociales, Universidad de Buenos Aires, v. 4, n. 14, jan./ mar., 2005.

. Colonialidad del Poder, Cultura y Conocimiento en América Latina. Anuário Mariateguiano. Lima: Amatua, v. IX, n. 9, 1997.

QUIJANO, A. e WALLERSTEIN, I. Americanity as a concept or the Americas in the modern world-system. International Social Science Journal, n. 134, nov. 1992.

SANTOS, T. dos. Imperialismo y dependencia. México: 1978

SAUER, S.; LEITE, S. P. Expansão agrícola, preços e apropriação de terra por estrangeiros no Brasil. Revista de Economia e Sociologia Rural [online], v. 50, n. 3, p. 503$524,2012$.

SERFATI, C. Militarismo e imperialismo: su actualidad en el siglo XXI. VIENTO SUR, n. 88, set. 2006.
SIAMIG - Sindicato da Indústria da Fabricação do Álcool no Estado de Minas Gerais. Relatório Econômico: Capital Estrangeiro no Setor Sucroalcooleiro Brasileiro, n. 007. Belo Horizonte/MG, 2009.

SILVA, M. A. de M. Expropriação da terra, violência e migração: camponeses do nordeste do Brasil nos canaviais paulistas. Cadernos CERU (USP), v. 19, p. 165180, 2008.

SILVA, M. A. M.; MARTINS, R. C. A degradação social do trabalho e da natureza no contexto da monocultura canavieira paulista. Sociologias (UFRGS. Impresso), v. 24 , p. 196-241, 2010.

VAKHRUCHEV, V. O neocolonialismo e os seus métodos. Lisboa: Prelo, 1975

VELHO, O. G. Capitalismo autoritário e campesinato: um estudo comparativo a partir da fronteira em movimento. Rio de Janeiro: DIFEL, 1979

. Frentes de expansão e estrutura agrária: estudo do processo de penetração numa área da Transamazônica. Rio de Janeiro: 1972.

VON DER WEID, J. M. Agro-combustíveis: Solução ou problema. In: ABRAMOVAY, R. (Org.). Biocombustíveis A energia da controvérsia. São Paulo: Editora Senac, 2009. 
